\begin{tabular}{|c|c|}
\hline Title & $\begin{array}{l}\text { Development of Lignin-Based Terpolyester Film and Its A pplication to Separator Material for Electric Double-Layer } \\
\text { Capacitor }\end{array}$ \\
\hline Author(s) & $\begin{array}{l}\text { Koda, Keiichi; T aira, Shogo; Kubota, A tsushi; I sozaki, Tomofumi; Y ou, X iangyu; U raki, Y asumitsu; Sugimura, } \\
\text { Kazuki; Nishio, Y oshiyuki }\end{array}$ \\
\hline Citation & $\begin{array}{l}\text { Journal of wood chemistry and technology, 39(3), 198-213 } \\
\text { https://doi.org/10.1080/02773813.2018.1562472 }\end{array}$ \\
\hline Issue Date & 2019-05-04 \\
\hline Doc URL & http:/hdl.handle.net/2115//7816 \\
\hline Rights & $\begin{array}{l}\text { This is an A ccepted Manuscript of an article published by Taylor \& Francis in Journal of Wood Chemistry and } \\
\text { Technology on } 4 \text { May 2019, available online: http://www.tandfonline.com/10.1080/02773813.2018.1562472. }\end{array}$ \\
\hline Type & article (author version) \\
\hline Additional Information & There are other files related to this item in HUSCAP. Check the above URL. \\
\hline File Information & Koda et al_rev ver HUSCAP.pdf \\
\hline
\end{tabular}

Instructions for use 


\title{
Development of lignin-based terpolyester film and its application to separator material for electric double-layer capacitor
}

\author{
Keiichi Koda, ${ }^{1, *}$ Shogo Taira, ${ }^{2}$ Atsushi Kubota, ${ }^{2}$ Tomofumi Isozaki, ${ }^{2}$ Xiangyu You, ${ }^{2}$ Yasumitsu \\ Uraki, ${ }^{1}$ Kazuki Sugimura, ${ }^{3}$ Yoshiyuki Nishio ${ }^{3}$ \\ ${ }^{1}$ Research Faculty of Agriculture, Hokkaido University, Sapporo 060-8589, Japan \\ ${ }^{2}$ Graduate School of Agriculture, Hokkaido University, Sapporo 060-8589, Japan \\ ${ }^{3}$ Graduate School of Agriculture, Kyoto University, Kyoto 606-8502, Japan \\ * Corresponding author, email address: cody@for.agr.hokudai.ac.jp
}

\begin{abstract}
For new application of technical lignins as separator material for electric double-layer capacitor (EDLC), we tried first to prepare bipolyester film by melt-polycondensation of polyethylene glycol lignin (PEGL) and maleic anhydride (MA). The EDLC assembled with this film, however, showed lower electrochemical performance than the reference EDLC with commercial cellulosic separator. Porous bipolyester film was then prepared and the resulting EDLC exhibited improved specific capacitance, but high intrinsic and charge transfer resistances. Non-porous terpolyester film was prepared next, using polyethylene glycol (PEG) 500,000 to improve flexibility of the film, which might lower the resistances. This film was flexible enough and provided the resulting
\end{abstract}


EDLC with superior electrochemical performance to the bipolyester film. EDLC with porous terpolyester film was finally prepared and showed the highest electrochemical performance, comparable to the reference EDLC. Porous morphology and flexibility were key factors to fabricate lignin-based self-standing film as separator material for high-performance EDLC.

Keywords: electric double-layer capacitor (EDLC), polyethylene glycol lignin (PEGL), terpolyester, separator, self-standing film

\section{Introduction}

Functionalization of lignin-based material is essential to expand application of isolated lignins. ${ }^{[1,2]}$ Woody biomass can be fully utilized as an alternative to fossil resources, when isolated lignin-based products are commercially in widespread use. Such material use of lignin on a commercial basis, however, is seen only in a limited area (e.g. cement dispersant from lignosulfonate), while most of industrially isolated lignins are burned, only to be used almost exclusively for energy recovery, ${ }^{[3]}$ Although energy recovery from lignin combustion is an important form of lignin utilization, it is not a high value-added use of lignin at the same time. Therefore, development of novel, value-added, functional material from isolated lignins is a key to full utilization of woody biomass.

Uraki and his research group proposed some possible applications by functionalization of isolated lignins into their amphipathic derivatives, such as cement dispersant, ${ }^{[4-6]}$ cellulase-aid agent, ${ }^{[7-10]}$ and thermosensitive gel with a unique swelling property. ${ }^{[11]}$. Uraki and coworkers 
have recently published papers on lignin-based EDLC, trying to develop key components of EDLC, such as electrode material ${ }^{[12-14]}$ from lignin-based activated carbon fibers. ${ }^{[15,16]}$ EDLC exhibits rapid charge/discharge performance (completed within a few seconds) and a long charge-discharge life cycle. ${ }^{[17]}$ As future demand for EDLC is expected to grow, ${ }^{[18]}$ our attempt has been made to develop organic components of EDLC other than electrode material such as separator material, using lignin-based polymer as a substitute for petroleum-derived synthetic polymer. Separator plays an important role in preventing electrodes from their direct electric contact (short circuit) and, at the same time, in helping ionic charge carriers (electrolytes) to permeate and transport rapidly. ${ }^{[19]}$ Cellulose and some synthetic polymers, as porous electric insulator, have conventionally been used as such separator material. ${ }^{[19]}$ Our target in this study is to develop lignin-based functional separator material for EDLC with high electrochemical performance.

We used polyethylene glycol lignin (PEGL), a type of organosolv lignin, as the major ingredient for the lignin-based polyester film. PEGL can be directly isolated from black liquor by a solvolysis pulping of cedar wood chip, using polyethylene glycol 400 (PEG 400), and a small amount of sulfuric acid as a catalyst. ${ }^{[20]}$ PEGL showed excellent thermal fusibility. ${ }^{[20]}$ It is generally known that PEG moiety (repeating units of ethylene oxide in PEG) can act as a soft segment when PEG is introduced to a polymer. ${ }^{[21]}$ PEG moiety is thus assumed to add flexibility and thermal fusibility to lignin skeleton. In addition, PEGL, as a polyol, can be expected to react with chemical reagents (e.g. electrophiles) more easily than other types of isolated lignin such as kraft lignin (KL) and soda lignin (SL), because PEGL has long ethylene oxide-repeating units each with a hydroxy group at their end, which locates far away from its phenyl propane skeleton of lignin, while KL and SL have hydroxy groups in the vicinity of their lignin skeleton. This 
difference in the distance of hydroxy groups from lignin skeleton, we anticipated, would probably be an important factor affecting the improved reactivity of PEGL with some electrophilic reagents such as carboxylic acid halide and anhydride, because the reactivity of hydroxy groups in PEGL are less likely to be affected by steric hindrance of lignin skeleton than that of hydroxy groups in KL and in SL.

In our earlier preliminary experiments, we tried to prepare polyester fiber by static interfacial polycondensation reaction of isolated lignins (PEGL, KL, and SL) with terephthaloyl chloride in a double-layered solvent (water/chloroform) system. As a result, formation of polyester from PEGL, KL, and SL was observed at room temperature at the interface of the double layers of the solvent system. The polyester was collected as fibrous material, by using a winder. The resulting PEGL-based polyester fiber was not so strong but could be subjected to mechanical test, while KL- and SL-based polyester fibers were too brittle to serve as a mechanical test specimen. Better reactivity of PEGL than that of KL and SL was thus confirmed empirically, as we anticipated. However, we did not make it to obtain polyester film under this reaction condition. Then, we changed our strategy. We tried to fabricate self-standing polyester film by melt-polycondensation in the absence of catalyst, using a mold and a hot press machine.

This study aims at developing lignin-based polyester film as separator material suitable for high electrochemical performance EDLC. We first fabricated bipolyester film, using PEGL and maleic anhydride (MA). Mechanical and thermal properties of the film, and electrochemical properties of EDLC assembled with the film were evaluated. We next prepared flexible terpolyester film for EDLC with higher electrochemical performance. In order to provide our polyester film with porous morphology and flexibility to improve electrochemical performance 
of the resulting EDLC, we finally tried to use sodium chloride ( $\mathrm{NaCl})$ and PEG 500,000, respectively.

\section{Materials and Methods}

\section{Reagents}

All reagents and materials used in this study were purchased from FUJIFILM Wako Pure Chemicals Co. (Osaka, Japan) unless otherwise mentioned. The reagents were of analytical grade and used as received.

\section{Preparation of PEGL from Japanese cedar wood chip by solvolysis}

PEGL was prepared, according to the procedure in our previous research work. ${ }^{[15]}$ Typically, wood chip (240 g on an oven-dry weight basis) of Japanese cedar (Cryptomeria japonica) was cooked in a 2 L-separable flask by a solvolysis pulping process at $160^{\circ} \mathrm{C}$ for 240 min, with PEG 400 (1200 g) and a catalytic amount (3.6 g) of 98\% sulfuric acid. The reaction was quenched by cooling down the flask in an ice-water bath. Black liquor and cedar pulp were separated by filtration. The pulp was further washed well and filtered several times, using $4.8 \mathrm{~L}$ in total of $80 \%(\mathrm{v} / \mathrm{v})$ aqueous 1,4-dioxane solution. The black liquor and the washings were mixed. The organic solvent (1,4-dioxane) in the mixture was removed under reduced pressure by rotary evaporation, and the resulting aqueous suspension was transferred to a 2 L-separable flask. The flask was placed in an oil bath, and heated at $140^{\circ} \mathrm{C}$ for $150 \mathrm{~min}$ with continuous stirring. 
After the flask was cooled down in an ice-water bath, the suspension was poured into $16 \mathrm{~L}$ of distilled water, and left standing overnight with stirring. The precipitate was collected by centrifugation at $11,600 \mathrm{G}$ at $4^{\circ} \mathrm{C}$ for $15 \mathrm{~min}$. The precipitate was suspended in fresh distilled water, and the resulting precipitate was collected again by centrifugation to remove the supernatant. This washing process was repeated several times until the supernatant began to become cloudy. The final precipitate was collected as dry solid material (PEGL) by lyophilization (yield: $43.2 \%$ on wood chip). This laboratory scale-prepared batch of PEGL was used in some preliminary experiments, prior to this study.

Another batch of PEGL was used throughout this study, which was kindly provided by a company (Harima Chemicals Group Inc., Tokyo, Japan). This company-provided batch of PEGL was prepared on a kg-scale under otherwise identical conditions as the lab scale-prepared batch of PEGL.

PEGLs were subjected to elemental analysis with a microcorder (JM 11: J-Science Lab. Co. Ltd., Kyoto, Japan), at Instrumental Analysis Division, Global Facility Center, Creative Research Institution, Hokkaido University. Determination of PEG content in PEGL, determination of hydroxy groups of PEGL by ${ }^{1} \mathrm{H}$ NMR analysis of acetylated PEGL, and thermomechanical analysis (TMA) of PEGL were performed, according to our previous study. ${ }^{[15]}$

\section{Characterization of PEGL by Fourier-transform infrared spectrometry (FT-IR)}

Functional groups of PEGL and PEGL-derived polyester film were characterized by FT-IR, using a spectrophotometer (IR FIS-50A; Bio-Rad Laboratories Inc., Tokyo, Japan). The sample 
$(2.0 \mathrm{mg})$ and potassium bromide (KBr: $100 \mathrm{mg})$ were mixed with a mortar and a pestle. A tablet was prepared from the mixture by compression in a vacuum mold. Scan rate was set at $5 \mathrm{kHz}$. Scanning range was $400-4000 \mathrm{~cm}^{-1}$ with a resolution of $4 \mathrm{~cm}^{-1}$. Number of scan was 128 .

\section{Preparation of lignin-based polyester film by melt-polycondensation of PEGL with MA and/or PEG analogues}

A thin mold (dimension of cavity: $50 \mathrm{~mm}$ in length $\times 50 \mathrm{~mm}$ in width $\times 50 \mu \mathrm{m}$ in depth) and a thick mold (50 mm in length $\times 50 \mathrm{~mm}$ in width $\times 100 \mu \mathrm{m}$ in depth) were prepared by assembling and fixing some sheets of poly (tetrafluoroethylene) [PTFE] film (NICHIAS Co., Tokyo, Japan), prior to melt-polycondensation reaction.

PEGL and MA were mixed at different charged ratios in a glove box under a nitrogen atmosphere at room temperature, using a mortar and a pestle. The charged ratios of MA to PEGL were expressed as the molar ratios of carboxy groups of the corresponding dicarboxylic acid of MA (i.e. maleic acid) to hydroxy groups of PEGL, denoted as $\mathrm{COOH}_{(\mathrm{MA})} / \mathrm{OH}_{(\mathrm{PEGL})}$ hereafter. The $\mathrm{COOH}_{(\mathrm{MA})} / \mathrm{OH}_{(\mathrm{PEGL})}$ ratios were $1 / 9,3 / 7,5 / 5,6.6 / 3.4,8 / 2$, and $9 / 1$. Part of the mixture $(0.18$ $\mathrm{g}$ for a thin mold, and $0.35 \mathrm{~g}$ for a thick mold) was cast in a mold cavity, and then covered with another sheet of PTFE film. The mixture in the PTFE mold was then subjected to meltpolycondensation at $200^{\circ} \mathrm{C}$ under a pressure of $5 \mathrm{MPa}$ for $4 \mathrm{~h}$, using a hydraulic hot-press machine (HP-300TL-S: Nisshin Science Co. Ltd., Tokyo, Japan). After cooling down, the resulting film was peeled off the PTFE mold and collected. 
The film was washed well with acetone and completely dried. Briefly, the film was soaked in acetone $(20-50 \mathrm{~mL})$ in a vial and the vial was placed in a shaking bath at $100 \mathrm{rpm}$ at room temperature for $3 \mathrm{~d}$. The solvent (acetone) was replaced with fresh one three times a day. The film was sandwiched between two sheets of dry filter paper to remove the solvent roughly, and then dried completely over $\mathrm{P}_{2} \mathrm{O}_{5}$ in a vacuum oven at $50^{\circ} \mathrm{C}$ under reduced pressure overnight. The dry film was subjected to mechanical test, FT-IR analysis, differential scanning calorimetry (DSC), dynamic mechanical analysis (DMA), and also used as separator material to assembly EDLC. The film was stored in a dark place at room temperature until used.

$\mathrm{NaCl}$ and/or PEG analogues (PEG 20,000, PEG 500,000, and PEG 2,000,000) were also used in separate experiments, and mixed independently with PEGL and MA under a nitrogen atmosphere in a glove box as described above. Charged weight ratio of sodium chloride to the mixture of PEGL and MA was fixed at $5 \mathrm{wt} \%$ and $10 \mathrm{wt} \%$, while that of PEG analogues was set at $10 \mathrm{wt} \%$ and $30 \mathrm{wt} \%$. When $\mathrm{NaCl}$ was used, the resulting film was washed well with distilled water and acetone to obtain porous film, and completely dried. Briefly, the film was soaked in distilled water $(20 \mathrm{~mL})$ in a vial and the vial was placed in a shaking bath at room temperature at $100 \mathrm{rpm}$ for $1 \mathrm{~d}$. The solvent (distilled water) was replaced with fresh one five times a day. The resulting film was further washed with acetone in a similar manner as above for another $2 \mathrm{~d}$, by replacing acetone with fresh one three times a day. The film was finally sandwiched between two sheets of dry filter paper to remove acetone roughly, and then dried completely over $\mathrm{P}_{2} \mathrm{O}_{5}$ in a vacuum oven at $50^{\circ} \mathrm{C}$ under reduced pressure overnight.

Microscopic observation of surface morphology of the lignin-based polyester film 
Morphology of the polyester film was observed under a three-dimensional (3-D) microscope (violet laser color 3-D profile microscope, VK-9510: Keyence, Osaka, Japan), and under a scanning electron microscope (SEM) (JSM-6301F, JOEL Ltd., Tokyo, Japan) at an accelerating voltage of $5 \mathrm{kV}$ after gold spattering.

\section{Mechanical test}

A specimen $(50 \mathrm{~mm}$ in length $\times 10 \mathrm{~mm}$ in width $\times 50 \mu \mathrm{m}$ in thickness $)$ was cut out of the PEGL-based polyester film and subjected to tensile test at a tensile rate of $0.5 \mathrm{~mm} / \mathrm{min}$ under a 1 kN load cell, using a universal testing machine (AGS-500D Autograph: Shimadzu, Kyoto, Japan) with a gauge width at $30 \mathrm{~mm}$. Thickness of the specimen was measured with an electronic digital external micrometer (MCD130-25, Niigata Seiki Co., Ltd., Sanjo, Japan).

\section{Differential scanning calorimetry (DSC) and dynamic mechanical analysis (DMA)}

Microstructure of bipolyester and terpolyester film was evaluated by DSC and DMA. Briefly, a specimen (5 mg) was sealed in an aluminum pan and subjected to DSC under a nitrogen flow, with a differential scanning calorimeter (DSC6200/Exstar6000: Seiko Instruments Inc., Chiba, Japan) on heating scans from room temperature to $150^{\circ} \mathrm{C}$ at a scan rate of $20.0^{\circ} \mathrm{C} / \mathrm{min}$ (first heating run), and then cooled down rapidly to $-100^{\circ} \mathrm{C}$ with liquid nitrogen. The specimen was heated again from $-100^{\circ} \mathrm{C}$ to $200^{\circ} \mathrm{C}$ at a scan rate of $20.0^{\circ} \mathrm{C} / \mathrm{min}$ (second heating run). Another specimen $(20 \mathrm{~mm} \times 5 \mathrm{~mm})$ was subjected to DMA, with a dynamic mechanical analyzer (DMS6100/EXSTAR6000: Seiko Instruments Inc., Chiba, Japan) in the measuring 
conditions: temperature range, $-100^{\circ} \mathrm{C}-250^{\circ} \mathrm{C}$; heating rate, $2.0^{\circ} \mathrm{C} / \mathrm{min}$; oscillatory frequency, $10 \mathrm{~Hz}$.

\section{Assembly of EDLC}

As ingredients of electrode material, commercial activated carbon, conductive carbon black (Alfa Aesar, Heysham, UK), and carboxymethylcellulose (CMC) sodium salt (85/5/10, $\mathrm{w} / \mathrm{w} / \mathrm{w}$ ) were used. A $2 \mathrm{wt} \%$ aqueous solution of CMC sodium salt was prepared, and then these ingredients were mixed to obtain slurry. The slurry was cast on a sheet of aluminum foil $(0.1 \mathrm{~mm}$ in thickness), and dried in an oven at $105^{\circ} \mathrm{C}$ overnight. Some small discs (16 $\mathrm{mm}$ in diameter) were punched out of the coated aluminum foil, and dried again in an oven at $105^{\circ} \mathrm{C}$ overnight.

The polyester film and the electrode material were soaked in an organic electrolyte solution (1 M triethylmethyl ammonium-tetrafluoroborate $\left(\mathrm{TEMABF}_{4}\right)$ [Tokyo Chemical Industry Co., Ltd., Tokyo Japan] in propylene carbonate [PC]). EDLC was then assembled with the ligninbased polyester film, electrodes, and cells for electrochemical measurement. As a reference EDLC, commercial cellulosic separator (Mitsubishi Paper Co. Ltd., Japan) was used in place of the polyester film.

\section{Evaluation of electrochemical properties of EDLC}

Electrochemical properties were evaluated, according to our previous work. ${ }^{[12,13]}$ Capacitance of EDLC was measured and calculated by cyclic voltammetry (CV). All CV profiles 
were monitored at a potential window from 0 to $3.0 \mathrm{~V}$ at a scan rate of $0.05 \mathrm{~V} / \mathrm{s}$. Intrinsic resistance and charge transfer resistance of EDLC were calculated from Niquist plot by electrochemical impedance spectroscopy (EIS). In both measurements, potentiostat/galvanostat workstation (Autolab PGSTAT302N FRA32M, Metrohm Autolab B.V., Tokyo, Japan) was used.

\section{Results and Discussion}

\section{Characterization of PEGL}

Carbon, hydrogen, and oxygen contents of PEGL were found $62.8 \%, 6.3 \%$, and $30.9 \%$, respectively. ${ }^{1} \mathrm{H}$ NMR analysis after acetylation of PEGL revealed that total hydroxy group content of PEGL was $7.0 \mathrm{mmol} / \mathrm{g}$, where aromatic and aliphatic hydroxy group contents were found $2.9 \mathrm{mmol} / \mathrm{g}$ and $4.1 \mathrm{mmol} / \mathrm{g}$, respectively. Glass transition temperature $\left(\mathrm{T}_{\mathrm{g}}\right)$ and thermal flow-starting temperature $\left(\mathrm{T}_{\mathrm{f}}\right)$ of PEGL were $114.9^{\circ} \mathrm{C}$ and $171.1^{\circ} \mathrm{C}$, respectively.

Figure 1 shows FT-IR spectra of PEGL and its reduced derivatives with $\mathrm{NaBH}_{4}$ with varying reaction time. Intensity of one band at around $1710 \mathrm{~cm}^{-1}$ was dropped by $\mathrm{NaBH}_{4}$ reduction, indicating the existence of easily-reducible unconjugated carbonyl group $(\mathrm{C}=\mathrm{O}$ stretching vibration). ${ }^{[22]}$. Because PEGL was prepared under an acidic condition, this easilyreducible part of $\mathrm{C}=\mathrm{O}$ group at around $1710 \mathrm{~cm}^{-1}$ can be attributed to the existence of Hibbert's ketone $^{[23]}$ in PEGL. Figure 2 shows FT-IR spectra of PEGL and the PEGL-derived bipolyester. Intensity of the band assigned to $\mathrm{C}=\mathrm{O}$ stretching vibration (carbonyl groups) at $1700-1800 \mathrm{~cm}^{-1}$

was increased with an increase in the charged molar ratio of $\mathrm{COOH}_{(\mathrm{MA})}$ to $\mathrm{OH}_{(\mathrm{PEGL}) \text {. Existence of }}$ 
this broad band explains that ester bond and/or carboxylic acid was formed ${ }^{[24]}$ by the reaction of PEGL with MA, depending on the charged ratio of MA to PEGL.

\section{PEGL-based bipolyester film prepared by melt-polycondensation and its mechanical properties}

As generally known, reactivity of acid chloride toward alcohol is much higher than that of acid anhydride. ${ }^{[25]}$ Nevertheless, we did not make it to obtain bipolyester film by the reaction of some commercial acid chloride-reagents, such as terephthaloly chloride, adipoyl chloride, and sebacoyl chloride, with PEGL. We found much more difficulty in handling such acid chlorides than MA in the molding process: those acid chloride-reagents began to react with PEGL too rapidly, once mixed with PEGL in a glove box under a nitrogen atmosphere even at room temperature. Moderate reactivity may be a key to successful preparation of PEGL-based polyester film by melt-polycondensation.

We then tried to fabricate flat polyester (bipolyester) film with the thickness of 50-100 $\mu \mathrm{m}$ by melt-polycondensation of PEGL and $\mathrm{MA}$ at $200^{\circ} \mathrm{C}$ under $5 \mathrm{MPa}$, at varying charged molar ratio of $\mathrm{COOH}_{(\mathrm{MA})} / \mathrm{OH}_{(\mathrm{PEGL})}$ (i.e. $1 / 9,3 / 7,5 / 5,6.6 / 3.4,8 / 2$ and 9/1). We obtained bipolyester film successfully at the molar ratio of $1 / 9,3 / 7,5 / 5,6.6 / 3.4$ (Table $1 \&$ Supplemental Material Figure S1). Table 1 also summarizes mechanical properties of PEGL-based bipolyester film from stress-strain curves obtained by mechanical test, at varying charged molar ratios $\left(\mathrm{COOH}_{(\mathrm{MA})} / \mathrm{OH}_{(\mathrm{PEGL})}\right)$. At a charged molar ratio of $6.6 / 3.4$, the obtained film showed the maximum tensile strength of $45.6 \mathrm{MPa}$ and the maximum tensile modulus of $2.4 \mathrm{GPa}$, respectively. 
Here is some discussion of why this charged molar ratio (6.6/3.4) of $\mathrm{COOH}_{(\mathrm{MA})} / \mathrm{OH}_{(\mathrm{PEGL})}$ was seemingly favorable to polycondensation reaction. It should be noted that apparently hydroxy groups in PEGL reacted with MA at 1 to 1 molar ratio, because 1 mole of MA is equivalent to 2 moles of carboxylic acid groups. It looks strange if formation of half-ester (or monoester; as shown in Figure 3 [1]) was the only reaction to occur at this molar ratio (6.6/3.4) and proceeded quantitatively to consume almost all hydroxy groups in PEGL, because this reaction itself is not a cross-linking reaction that leads to an increase in mechanical strength of the resulting polyester film (Table 1). FT-IR spectra in Figure 2 demonstrates that this reaction [1] did not proceed quantitatively at all because considerable amounts of hydroxy groups were still found to exist after polycondensation reaction at any charged molar ratios. A mole of halfester could further react with another mole of hydroxy group to form a mole of diester (shown in Figure $3[2]$ ) at high temperature (c.a. above $\left.100^{\circ} \mathrm{C}\right),{ }^{[26]}$ though carboxylic acid group in the halfester is less reactive than acid anhydride. ${ }^{[25]}$ This reaction could be a cross-linking reaction among PEGL molecules. Furthermore, MA might have reacted with PEGL by other types of side reaction due to the existence of carbon-carbon double bond in $\mathrm{MA},{ }^{[26]}$ which could also contribute to a crosslinking structure among PEGL molecules (Figure 3 [3] \& [4]). Since reaction of MA is thus complicating ${ }^{[26,27]}$ as discussed above, a full explanation of why this molar ratio (6.6/3.4) was observed to be favorable to prepare polyester film cannot be made stoichiometrically at this moment.

However, molecular mobility might be a key word to make a possible explanation. PEGL, as a polyol component, is a polymer showing poorer molecular mobility than MA, a lowermolecular mass dicarboxylic acid derivative. Thus, it is understandable that increased charged molar ratio $\left(\mathrm{COOH}_{(\mathrm{MA})} / \mathrm{OH}_{(\mathrm{PEGL})}\right)$ increased the reactivity of MA and PEGL until it reached to 
the maximum limit. On the other hand, since fixed amounts ( $0.18 \mathrm{~g}$ and $0.35 \mathrm{~g})$ of PEGL-MA mixture was used in this study, self-standing polyester film was not able to be obtained at extremely high charged molar ratios (8/2 and 9/1) of MA to PEGL, possibly due to the insufficient amount of hydroxy groups in PEGL charged.

\section{Evaluation of electrochemical properties of EDLC with PEGL-based bipolyester film}

Specific capacitance of the assembled EDLC with PEGL-based bipolyester film was calculated by cyclic voltammetry $(\mathrm{CV})^{[12]}$ as the following equation.

$$
C_{1.5}=\frac{4 I}{m \cdot V / t}
$$

where $\mathrm{C}_{1.5}$ is a proximate value of specific capacitance calculated at an intermediate value $(1.5 \mathrm{~V})$ in the potential range $(0-3.0 \mathrm{~V})$, $\mathrm{I}$ is the current formed at $1.5 \mathrm{~V}, \mathrm{~m}$ is the total weight of electrode material, and V/t is the potential scanning rate. A CV curve of this EDLC (Figure 4; left, gray solid line) showed a very narrow rectangular shape or the upper curve nearly overlapped with the lower curve, indicating this EDLC has almost no capacitance. Its specific capacitance was found to be only $4.3 \mathrm{~F} / \mathrm{g}$ (Table 2). This value was much lower than that of EDLC with commercial cellulose-based separator $(74.8 \mathrm{~F} / \mathrm{g})$.

Intrinsic resistance was obtained at the intercept on the $Z^{\prime}$ axis in Nyquist plot of electrochemical impedance spectroscopy (EIS: typically shown as in Figure 4; right) and charge transfer resistance was estimated from the chord length of the semi-circle in a high-frequency region of the Nyquist plot. ${ }^{[12]}$ Intrinsic resistance $(117.9 \Omega)$ and charge transfer resistance (486.6 
$\Omega$ ) of the EDLC with the PEGL-based bipolyester film were much higher than those of the EDLC with a cellulose separator (1.2 $\Omega$ and $2.4 \Omega$, respectively) [Table 2]. We assumed that the poor performance was caused by little or no porous morphology of the film, which lead to insufficient permeation of electrolytes through the separator.

Porous film, then, was the next target to fabricate. Porous film was successfully fabricated by the addition of $\mathrm{NaCl}$ particles during the molding process prior to melt-polycondensation, followed by washing out the $\mathrm{NaCl}$ particles from the resulting film with sufficient amount of distilled water after melt-polycondensation (Figure 5). EDLC with the porous bipolyester film showed better electrochemical properties than that with the non-porous bipolyester film (Table 2). The specific capacitance was $59.1 \mathrm{~F} / \mathrm{g}$, the charge transfer resistance was $28.7 \Omega$, and the intrinsic resistance was $26.5 \Omega$. However, those electrochemical properties were still poorer than those with cellulosic separator, intrinsic resistance in particular. Such low electrochemical performance was probably caused by the poor flexibility of the polyester film. This film exhibited limited elasticity, and consequently the contact between electrodes and separator were assumed inadequate. Since it is likely that intrinsic resistance depended on the contact, we tried next to prepare flexible polyester film to overcome this problem.

\section{Fabrication of PEGL-based terpolyester film and its mechanical properties}

We tried to use PEG analogues (PEG 20,000, PEG 500,000, and PEG 2,000,000) as polyols other than PEGL to prepare more flexible polyester film, because ethylene oxide repeating units can act as a soft segment of PEG-derived polymer. ${ }^{[21]}$ Our target film was successfully prepared by the addition of PEG 500,000 at $30 \mathrm{wt} \%$ of the total weight of the mixture of MA and PEGL 
before melt-polycondensation reaction at the charged molar ratio of 6.6/3.4

$\left(\mathrm{COOH}_{(\mathrm{MA})} / \mathrm{OH}_{(\mathrm{PEGL})}\right)$. This terpolyester film showed the highest elongation $(94 \%)$ of all the film examined and flexible enough to fold it like a "paper airplane" without breakage (Figure 6). Its tensile strength and tensile modulus, calculated and summarized in Table 3, showed the lowest values (3.8 MPa and $13 \mathrm{MPa}$, respectively). This result indicates the film can act as an elastomer-like polymer. Although mechanical strength of this terpolyester film is not so strong, this drawback would probably not cause a serious problem, supposing the separator material is protected against external stress by other EDLC components such as electrode material and external packaging. Except for the $30 \mathrm{wt} \%$ incorporation of PEG 500,000, most of our attempts to add PEG analogues as the third ingredient were found to be unsuccessful (Table 3). The resulting terpolyester film at $10 \mathrm{wt} \%$ incorporation was not as strong as the bipolyester film with poor elongation (flexibility).

\section{Thermal property of polyester}

Figure 7 (left) demonstrates DSC thermograms obtained in the second heating scan for bipolyester and terpolyester films. The bipolyester film showed only a $T_{g}$ signal centering ca. $155^{\circ} \mathrm{C}$. For the terpolyester film, we observed a glass transition in a range of $-45-5^{\circ} \mathrm{C}\left(\mathrm{T}_{\mathrm{g}}=-\right.$ $28^{\circ} \mathrm{C}$ ) and a small endothermic peak at $50^{\circ} \mathrm{C}$. We confirmed that this endothermic peak displays a melting point $\left(\mathrm{T}_{\mathrm{m}}\right)$ of PEG 500,000 moiety in the terpolyester film, and not the peak by enthalpy relaxation that often appears near $T_{\mathrm{g}}{ }^{[28,29]}$ The $\mathrm{T}_{\mathrm{m}}$ signal was actually more noticeable in the first heating scan. Meanwhile, the value of $\mathrm{T}_{\mathrm{g}}=-28^{\circ} \mathrm{C}$ is appreciably higher compared to $\mathrm{T}_{\mathrm{g}} \approx-60^{\circ} \mathrm{C}^{[30]}$ reported for high-molecular-weight PEGs, indicating a certain compatibility of 
MA-modified PEGL with PEG 500,000 in the amorphous state. These results suggest that the terpolyester film contains some amount of ordered domains in which a bundle of molecular chains of PEG 500,000 reside, in addition to the compatibly mixed polymer amorphous regions.

Figure 7 (right) illustrates DMA data for bipolyester and terpolyester films. No curve for storage elastic modulus (E') or loss elastic modulus (E") of bipolyester film was obtained below $20^{\circ} \mathrm{C}$ due to the fragility and breakage of the bipolyester film in the lower temperature side. This film solely exhibited a descent behavior of $\mathrm{E}^{\prime}$ and $\mathrm{E}$ " above $170^{\circ} \mathrm{C}$ before the degradation became noticeable above $250^{\circ} \mathrm{C}$. On the other hand, $\mathrm{E}^{\prime}$ and $\mathrm{E}^{\prime \prime}$ of terpolyester film were easily observed at any temperature examined, suggesting that the terpolyester film was more stable in a wide temperature range than bipolyester film. Definitely, the terpolyester film retained its clear rectangular film shape even after the thermomechanical measurement. The film gave a principal E" peak at around $0^{\circ} \mathrm{C}$, and a sharp drop in $\mathrm{E}^{\prime}$ and $\mathrm{E}^{\prime \prime}$ at $55^{\circ} \mathrm{C}$. Considering this DMA and the DSC data, it can be reasonably taken that PEG moiety in the terpolyester film was partially melted and thus softened on heating without impairing the film form. These results would suggest the occurrence of micro-phase separated (sea-islands) structure in the terpolyester film; the dispersed island domains can also contribute to the adequate tenacity of film at and below room temperature.

In view of the fact that this terpolymer film was flexible enough and was not dissolved in water or organic solvents due to the presence of lignin, the film was thought to be applicable to separator material for EDLC where the film closely contacts with other EDLC components such as electrode and organic or inorganic electrolyte solution. 


\section{Assembly of EDLC with PEGL-based terpolyester film and its electrochemical properties}

The terpolyester film was used as separator to assembly EDLC. As shown in Figure 4 (left), this EDLC, using non-porous terpolyester film, gave a clear rectangular shape in cyclic voltammogram. The CV curve indicates that this EDLC has a large electrostatic capacitance. Actually, the specific capacitance of the EDLC was calculated to be $69.8 \mathrm{~F} / \mathrm{g}$ (Table 2), which accounted for $93 \%$ of the specific capacitance of the EDLC with cellulosic separator $(74.8 \mathrm{~F} / \mathrm{g})$. Surprisingly, the specific capacitance of this EDLC with the non-porous terpolyester film $(69.8$ $\mathrm{F} / \mathrm{g})$ was even higher than that of the EDLC assembled with porous bipolyester film $(59.1 \mathrm{~F} / \mathrm{g})$. Intrinsic resistance of EDLC with this non-porous terpolyester film was drastically decreased to as low as $4.9 \Omega$, which is superior to that of EDLC with the porous bipolyester film (26.5 $\Omega)$

[Table 2]. Therefore, authors thought that flexibility of the separator film was an important factor to fabricate high performance EDLC. In addition to the flexibility reason (i.e. film contact with other EDLC components), SEM observation (Figure 8 [A] and [B]) might give another possible explanation of why non-porous terpolyester film (without $\mathrm{NaCl}$ treatment) gave better electrochemical performance of EDLC than porous bipolyester film (with $\mathrm{NaCl}$ treatment). No distinct porous morphology was observed on the non-porous terpolyester film before acetone wash (Figure $8[\mathrm{~A}]$ ), while very finely wrinkled and/or finely porous structure was observed on the "non-porous" terpolyester film after the acetone wash (Figure $8[\mathrm{~B}]$ ). The authors thought that this finely wrinkled or porous structure appeared by the removal of unreacted ingredients, such as PEG 500,000, from the film. The difference in the surface morphology of the seemingly "non-porous" terpolyester film with and without acetone wash, also gave us an insight to the importance of macroscopically-porous structure of separator material for EDLC with high electrochemical performance. 
The intrinsic resistance of EDLC with the "non-porous" terpolyester film (4.9 $\Omega)$, in fact, was still slightly higher than that of EDLC with cellulosic separator $(1.2 \Omega)$. We thought that the electrochemical performance of this EDLC is still unsatisfactory. We also thought that the electrochemical performance would probably be drastically improved by the conversion of this "non-porous" terpolyester (acetone-washed) film into macroscopically "porous" one, as we observed in bipolyester film (Table 2). The "porous" structure in terpolyester film was thus prepared intentionally, by a treatment with $\mathrm{NaCl}$ particles.

Figure $8[C]$ and $[D]$ demonstrate 3-D microscopic images of the acetone-washed terpolyester film before and after $\mathrm{NaCl}$ treatment, respectively. Porous morphology of the terpolyester film is clearly seen after the $\mathrm{NaCl}$ treatment (Figure $8[\mathrm{D}]$ ), just as seen in porous bipolyester film in Figure 5 (right). The importance of this macroscopically "porous" structure can be proved, if electrochemical performance of EDLC with the "porous" terpolyester was shown to be better than the EDLC with the "non-porous" terpolyester film.

It was also found by 3-D microscopic observation that the porous terpolyester film had $61.5 \pm 3.4$ pores $/ \mathrm{mm}^{2}$ on the surface with the average pore diameter of $33.5 \pm 0.6 \mu \mathrm{m}$. Surface roughness of the non-porous and porous terpolyester films (Figure $8[\mathrm{C}]$ and [D], respectively) was also evaluated (Table 4), according to International Organization for Standardization (ISO) International Standard $4287 .{ }^{[31]}$ It is clear that $\mathrm{NaCl}$ treatment added rough surface morphology to the terpolyester film.

CV curve for EDLC with the porous terpolyester film gave slightly larger area than that for EDLC with its non-porous counterpart (Figure 4; left). Specific capacitance of EDLC with this porous terpolyester film was calculated to be as high as $84.2 \mathrm{~F} / \mathrm{g}$, which overwhelmed that of 
EDLC with commercial cellulosic separator $(74.8 \mathrm{~F} / \mathrm{g})$ [Table 2]. Charge transfer resistance of EDLC with the porous terpolyester film was decreased to $1.6 \Omega$ (Table 2), which was even lower than that of EDLC with commercial cellulosic separator $(2.4 \Omega)$. Intrinsic resistance of EDLC with the porous terpolyester film was found to be $8.8 \Omega$, which was higher than that of EDLC with non-porous terpolyester film (4.9 $\Omega$ ). At this moment, however, we think this is only a technical problem with an assembly process of EDLC. In terms of specific capacitance and charge transfer resistance, porous terpolyester film was thus proved to serve as good separator material.

In Summary, we have succeeded in preparing lignin-based terpolyester film as high performance separator material, by adding flexibility and porous (rough) morphology to the film, using PEG 500,000 and $\mathrm{NaCl}$, respectively.

\section{Conclusions}

Novel, lignin-based self-standing terpolyester film has been developed, using PEGL, MA, and PEG 500,000. Its applicability and suitability for separator material for EDLC were verified. This lignin-based terpolyester film was found flexible enough by mechanical and thermal analyses, probably giving good contact and adhesiveness to the other EDLC components such as electrodes. The terpolyester film was non-soluble in water or in organic solvents, and thus can be used in organic or inorganic electrolyte solution. As porous morphology of the film was also supposed to be another important factor for separator material, porous terpolyester film was prepared by using $\mathrm{NaCl}$ and the EDLC with the porous film was assembled. The EDLC showed an excellent electrochemical performance, which was almost comparable to and even better than 
the EDLC with commercial cellulose separator. This study presents a new application of isolated lignin by functionalization, which would serve as a sustainable utilization of woody biomass.

\section{Funding Details}

This research work was financially supported by a grant from the Ministry of Agriculture, Forestry and Fisheries of Japan, Development of Technologies for Biofuel Production Systems in Rural Areas (Rural Biomass Research Project, 2012-2015).

\section{Disclosure Statement}

The authors declare no conflict of interest.

\section{Acknowledgements}

We are grateful to the Ministry of Agriculture, Forestry and Fisheries of Japan, for the financial support to this research work by a grant, Development of Technologies for Biofuel Production Systems in Rural Areas (Rural Biomass Research Project, 2012-2015). Our gratitude also goes to Instrumental Analysis Division, Global Facility Center, Creative Research Institution, Hokkaido University, for elemental analysis upon our request.

\footnotetext{
Abbreviations

$\mathrm{CMC}$, carboxymethylcellulose; CV, cyclic voltammetry (cyclic voltammogram); DMA, dynamic mechanical analysis; DSC, differential scanning calorimetry; EDLC, electric double-layer
} 
capacitor; EIS, electrochemical impedance spectroscopy; FT-IR, Fourier transform infrared spectrometry; KL, kraft lignin; MA, maleic anhydride; PC, propylene carbonate; PEG, polyethylene glycol; PEGL, polyethylene glycol lignin; PTFE, poly (tetrafluoroethylene); SEM, scanning electron microscope (scanning electron microscopy); SL, soda lignin; $\mathrm{TEMABF}_{4}$, triethylmethyl ammonium-tetrafluoroborate; $\mathrm{T}_{\mathrm{f}}$, thermal flow-starting temperature; $\mathrm{T}_{\mathrm{g}}$, glass transition temperature; $\mathrm{T}_{\mathrm{m}}$, melting point; TMA, thermomechanical analysis.

\section{References}

1. Upton, B.M.; Kasko, A.M. Strategies for the conversion of lignin to high-value polymeric materials: Review and perspective. Chem. Rev. 2016, 116, 2275-2306.

2. Laurichesse S.; Avérous, L. Chemical modification of lignins: Towards biobased polymers. Prog. Polym. Sci. 2014, 39(7), 1266-1290.

3. Vishtal, A.; Kraslawski, A. Challenges in industrial applications of technical lignins. Bioresources 2011, 6(3), 3547-3568.

4. Homma, H.; Kubo, S.; Yamada, T.; Matsushita, Y.; Uraki, Y. Preparation and characterization of amphiphilic lignin derivatives as surfactants. J. Wood Chem. Technol. 2008, 28(4), 270-282.

5. Homma, H.; Kubo, S.; Yamada, T.; Koda, K.; Matsushita, Y.; Uraki, Y. Conversion of technical lignins to amphiphilic derivatives with high surface activity. J. Wood Chem. Technol. 2010, 30(2), 164-174.

6. Aso, T.; Koda, K.; Kubo, S.; Yamada, T.; Nakajima, I.; Uraki, Y. Preparation of novel lignin-based cement dispersants from isolated lignins. J. Wood Chem. Technol. 2013, 33(4), 286-298. 
7. Uraki, Y.; Ishikawa, N.; Nishida, M.; Sano, Y. Preparation of amphiphilic lignin derivative as a cellulase stabilizer. J. Wood Sci. 2001, 47(4), 301-307.

8. Winarni, I.; Oikawa, C.; Yamada, T.; Igarashi, K.; Koda, K.; Uraki, Y. Improvement of enzymatic saccharification of unbleached cedar pulp with amphipathic lignin derivatives. Bioresources 2013, 8(2), 2195-2208.

9. Winarni, I.; Koda, K.; Waluyo, T.K.; Pari, G.; Uraki Y. Enzymatic saccharification of soda pulp from sago starch waste using sago lignin-based amphipathic derivatives. J. Wood Chem. Technol. 2014, 34(3), 157-168.

10. Chen, N.; Yamamoto, Y.; Koda, K.; Tamai, Y.; Uraki, Y. Amphipathic lignin derivatives to accelerate simultaneous saccharification and fermentation of unbleached softwood pulp for bioethanol production. Bioresour. Technol. 2014, 173, 104-109.

11. Nishida, M.; Uraki, Y.; Sano, Y. Lignin gel with unique swelling property. Bioresour. Technol. 2003, 88(1), 81-83.

12. You, X.; Koda, K.; Yamada, T.; Uraki, Y. Preparation of electrode for electric double layer capacitor from electrospun lignin fibers. Holzforschung 2015, 69(9), 1097-1106.

13. You, X.; Koda, K.; Yamada, T.; Uraki, Y. Preparation of electric double layer capacitors (EDLCs) from two types of electrospun lignin fibers. Holzforschung 2016, 70(7), 661-671.

14. You, X.; Koda, K.; Yamada, T.; Uraki, Y. Preparation of high-performance internal tandem electric double-layer capacitors (IT-EDLCs) from melt-spun lignin fibers. J. Wood Chem. Technol. 2016, 36(6), 418-431.

15. Lin, J.; Kubo, S.; Yamada, T.; Koda, K.; Uraki, Y. Chemical thermostabilization for the preparation of carbon fibers from softwood lignin. Bioresources 2012, 7(4), 5634-5646. 
16. Lin, J.; Koda, K.; Kubo, S.; Yamada, T.; Enoki, M.; Uraki Y. Improvement of mechanical properties of softwood lignin-based carbon fibers. J. Wood Chem. Technol. 2014, 34(2), $111-121$.

17. You, B.; Wang, L.; Yao, L.; Yang, J. Three dimensional N-doped graphene-CNT networks for supercapacitor. Chem. Comm. 2013, 49, 5016-5018.

18. Shown, I.; Ganguly, A; Chen, L.-C.; Chen, K.-H. Conducting polymer-based flexible supercapacitor. Energ. Sci. Eng. 2015, 3(1), 2-26.

19. Arora, P.; Zhang, Z.M. Battery separators. Chem. Rev. 2004, 104(10), 4419-4462.

20. Takahashi, S.; Hosoya, S.; Hattori M.; Morimoto, M.; Uraki, Y.; Yamada T. Performance of softwood soda-anthraquinone lignin-polyethylene glycol derivatives as water-reducing admixture for concrete. J. Wood Chem. Technol. 2015, 35(5), 348-354.

21. Kolahdoozan, M.; Mirsafaei, R.; Mallakpour, S. Synthesis and properties of new highly soluble poly(amide-ester-imide)s containing poly(ethylene glycol) as a soft segment. Polym. Bull. 2012, 68, 1239-1254.

22. Funaoka, M.; Kako, T.; Abe, I. Condensation of lignin during heating of wood. Wood Sci. Technol. 1990, 24(3), 277-288.

23. Cramer, A.B.; Hunte, M. J.; Hibbert, H. Studies on lignin and related compounds. XXXV. The etanolysis of spruce wood. J. Am. Chem. Soc. 1939, 61, 509-516.

24. Xiao, B.; Sun, X.F.; Sun, R.C. The chemical modification of lignins with succinic anhydride in aqueous systems. Polym. Degrad. Stab. 2001, 71(2), 223-231.

25. Carboxylic acid derivatives. In Organic chemistry: Structure and function, 6th ed.; Vollhardt, K.P.C, Schore, N.E., eds.; W.H. Freeman and Company, New York, 2011, 925-970. 
26. Pandit, S.B.; Nadkarni, V.M. Toughening of unsaturated polyesters by reactive liquid polymers. 1. Synthesis and characterization of the modifiers. Ind. Eng. Chem. Res. 1993, 32(12), 3089-3099.

27. Friedman, M.; Garti, N. Maleyl esters of monoglycerides of saturated fatty acids. J. Am. Oil Chem. Soc. 1983, 60(6), 1134-1141.

28. Dogan, S.K.; Gumus, S.; Aytac, A.; Ozkoc G. Properties of modified ethylene terpolymer/poly(lactic acid) blends based films. Fibers Polym. 2013, 14(9), 1422-1431.

29. Pan, P.; Zhu, B.; Inoue, Y. Enthalpy relaxation and embrittlement of poly(L-lactide) during physical aging. Macromolecules 2007, 40(26), 9664-9671.

30. Bailey, F.E., Jr.; Koleske, J.V. Poly(ethylene oxide).; Academic Press: New York, USA, 1976.

31. ISO International Standard 4287:1997. http://www.iso.org/obp/ui/\#iso:std:iso:4287:ed1:vl:fr (accessed December 18, 2018). 


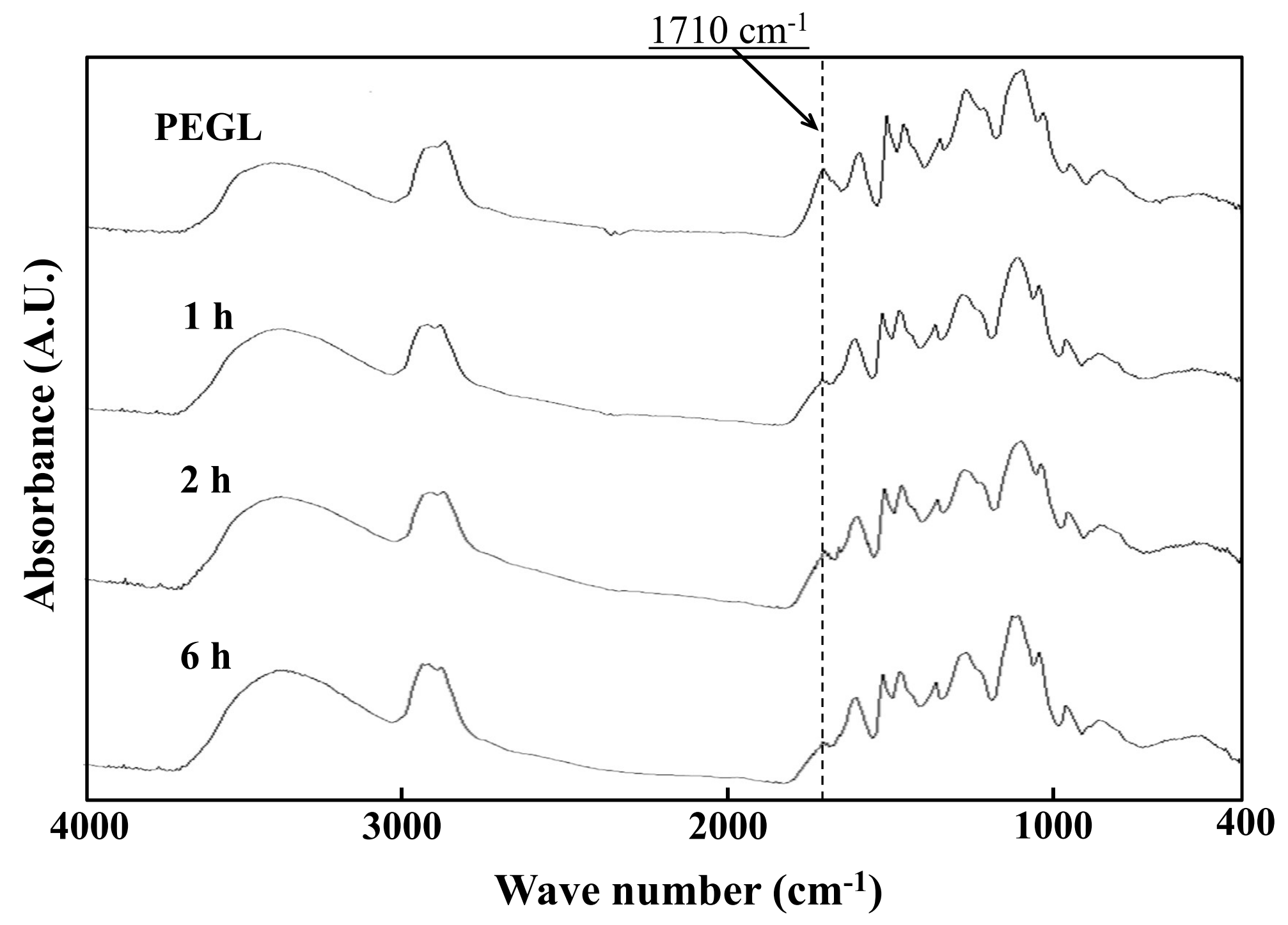

Fig. 1 

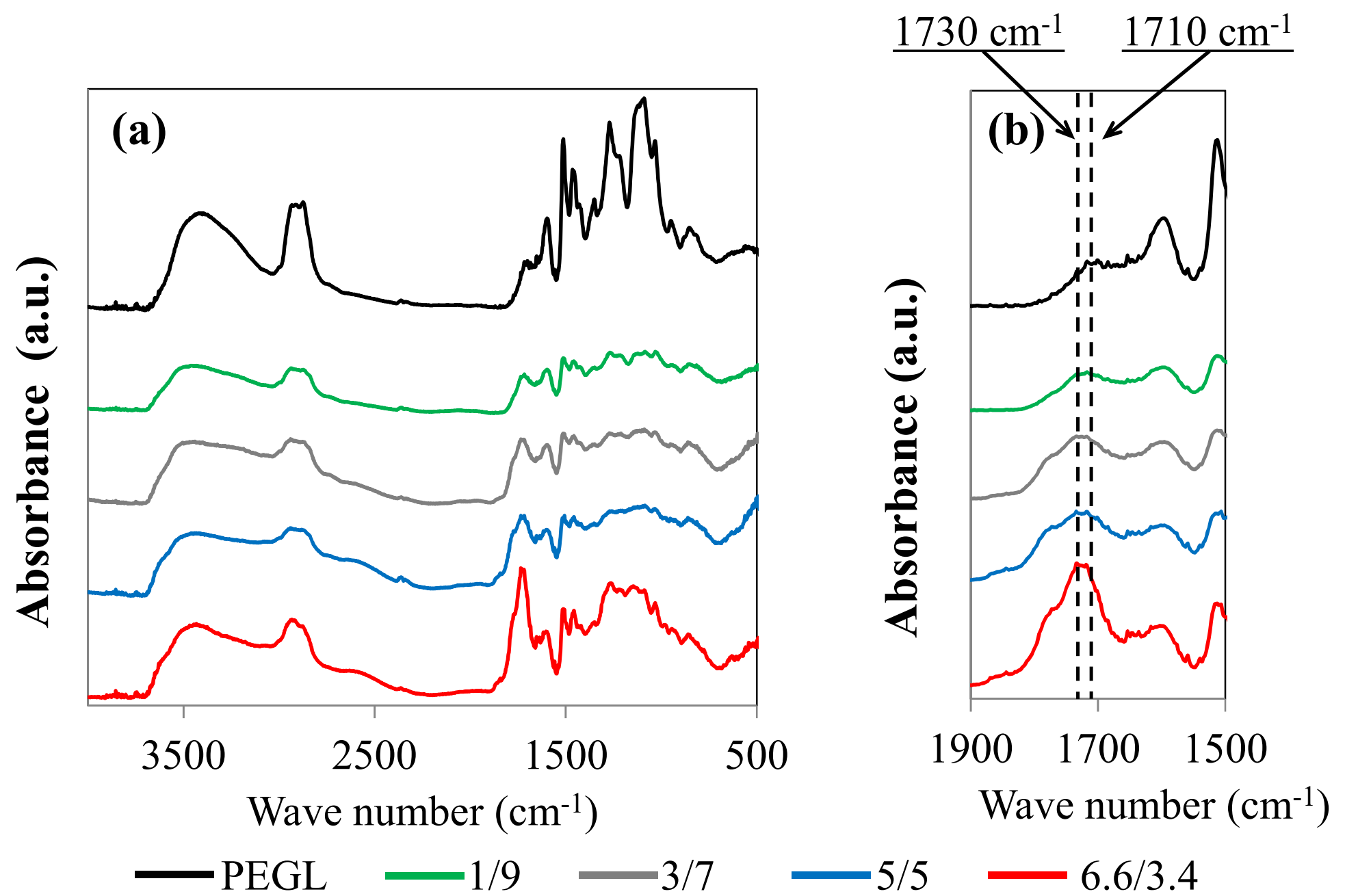

Fig. 2 
$\mathrm{Lig}-[\mathrm{OH}]_{\mathrm{n}}+\mathrm{O}=\left\langle\underset{\mathrm{O}}{\mathrm{Lig} \longrightarrow \mathrm{OH}]_{\mathrm{n}-1}} \underset{\mathrm{OHO}}{=\mathrm{O}}=\mathrm{O}\right.$

[1]

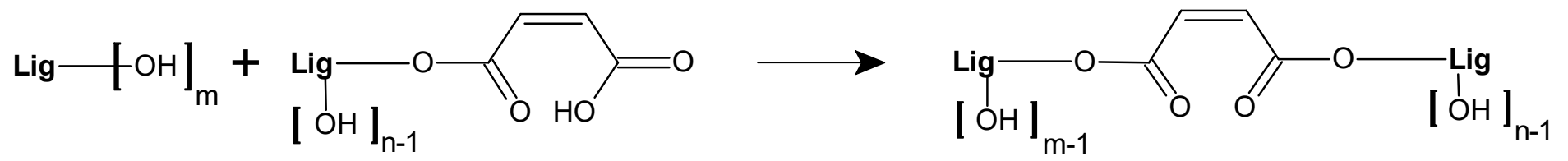

[2]
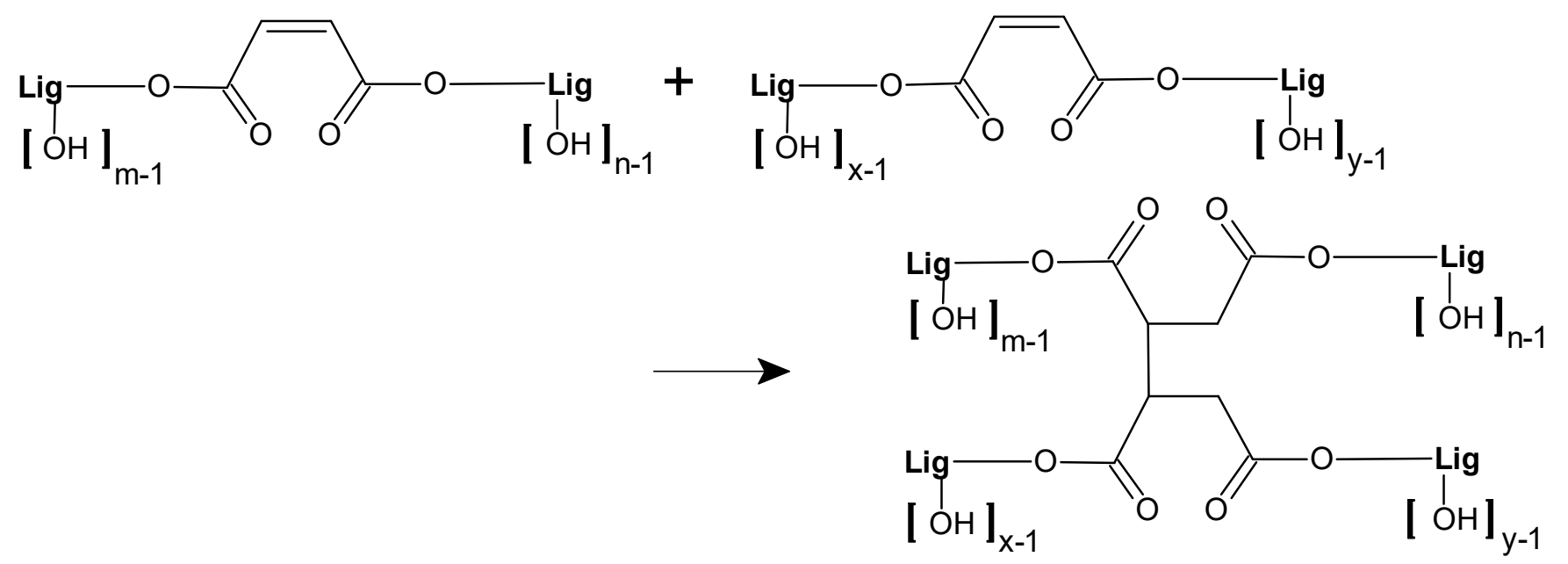

[3]

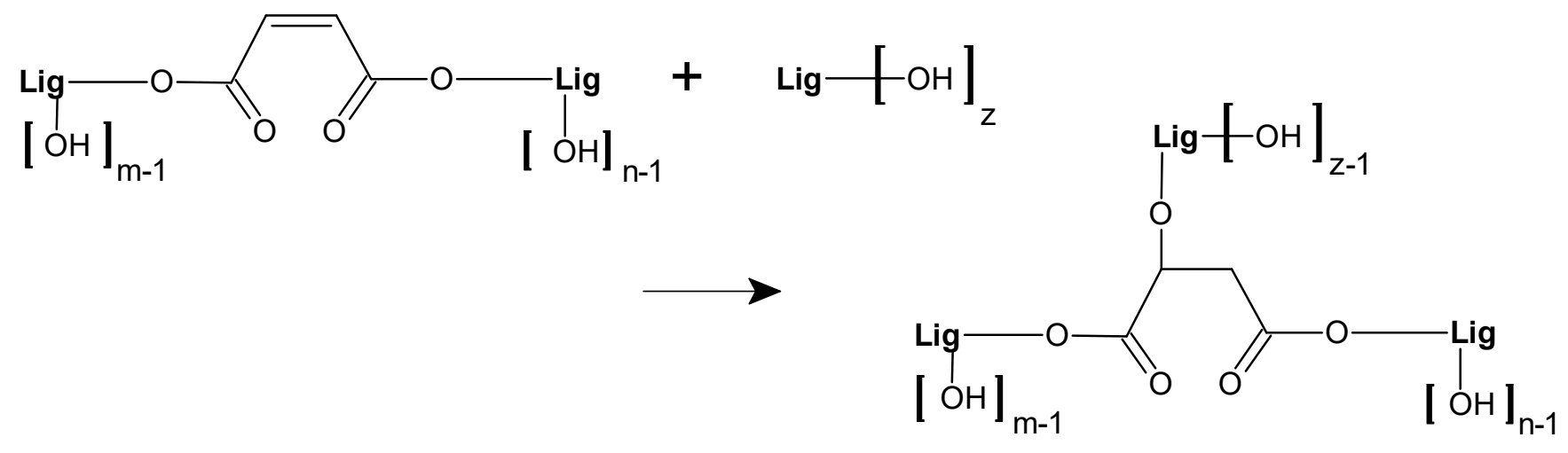

[4]

Fig. 3 


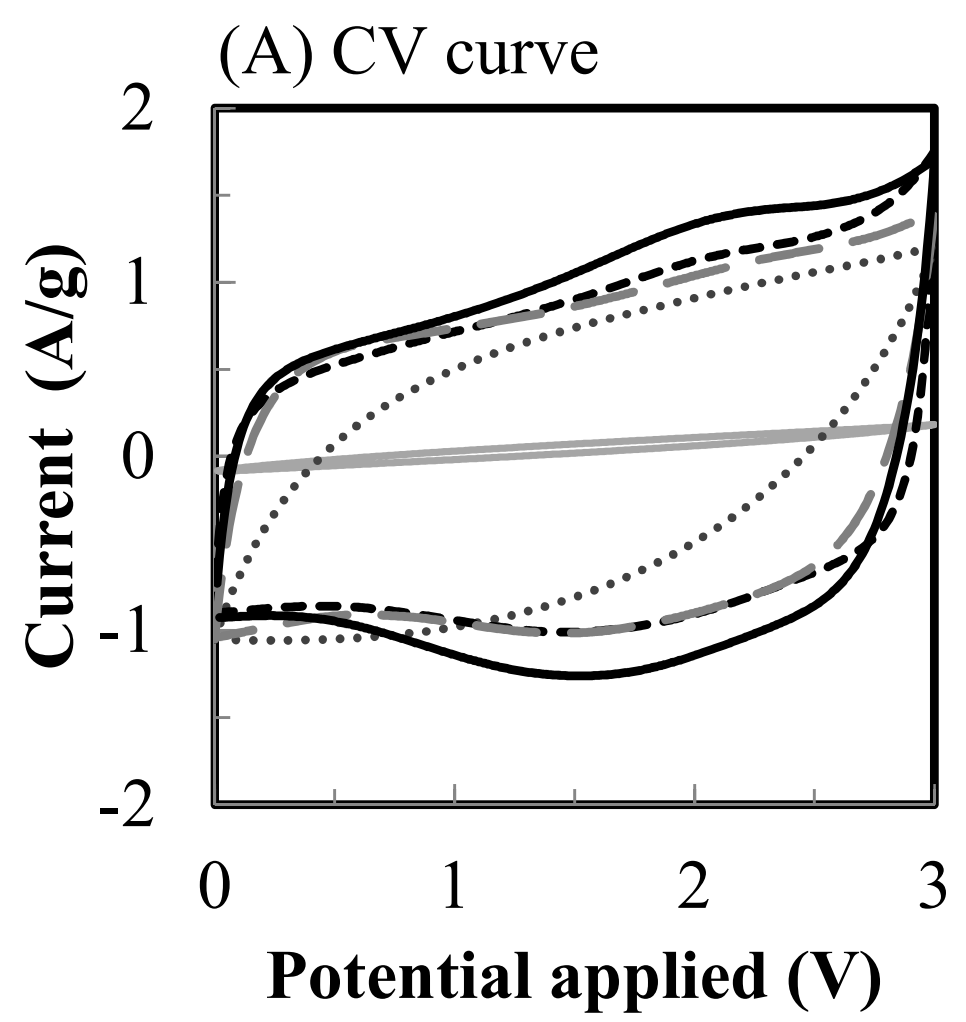

non-porous bipolyester film porous bipolyester film

— non-porous terpolyester film

porous terpolyester film

------ cellulosic paper (reference)

Scan rate: $0.05 \mathrm{~V} / \mathrm{s}$

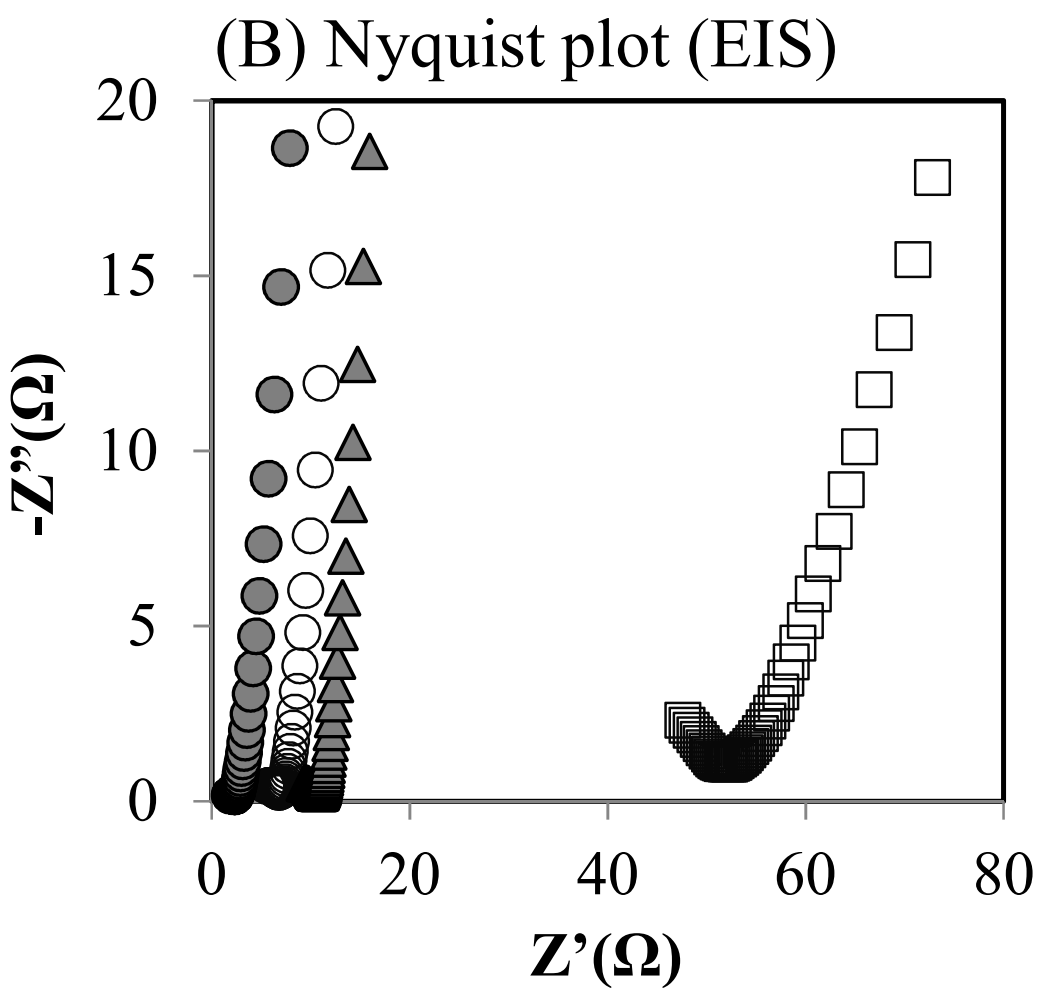

$\square$ porous bipolyester film

non-porous terpolyester film

$\Delta$ porous terpolyester film

$O$ cellulosic paper (reference)

Fig. 4 


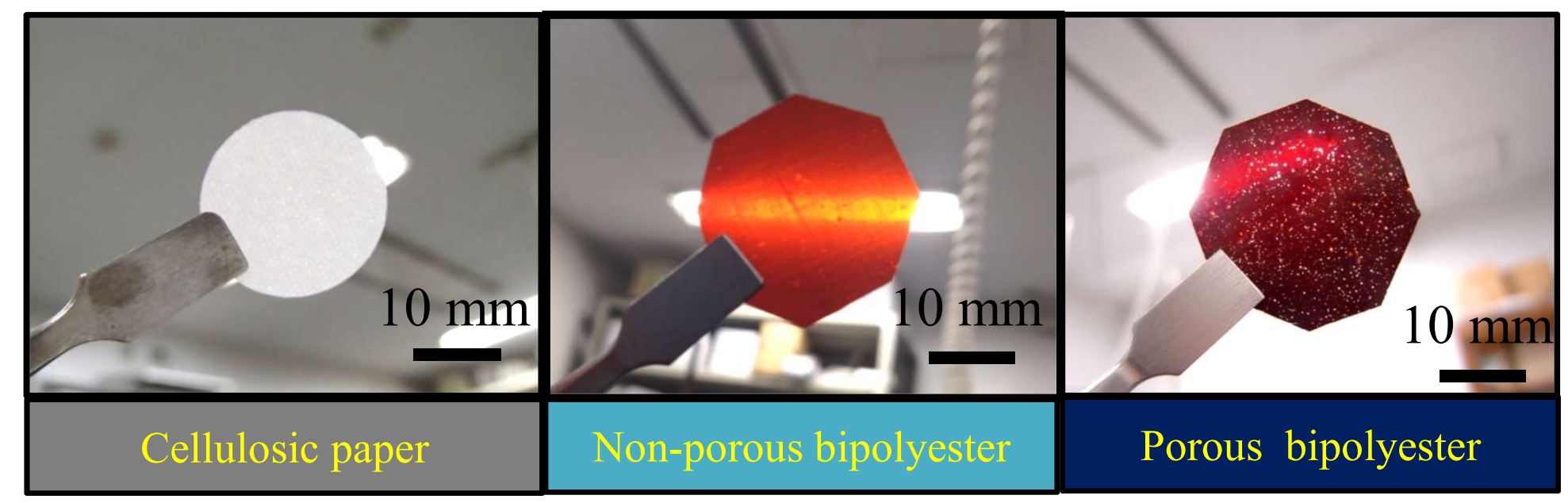

Fig. 5 


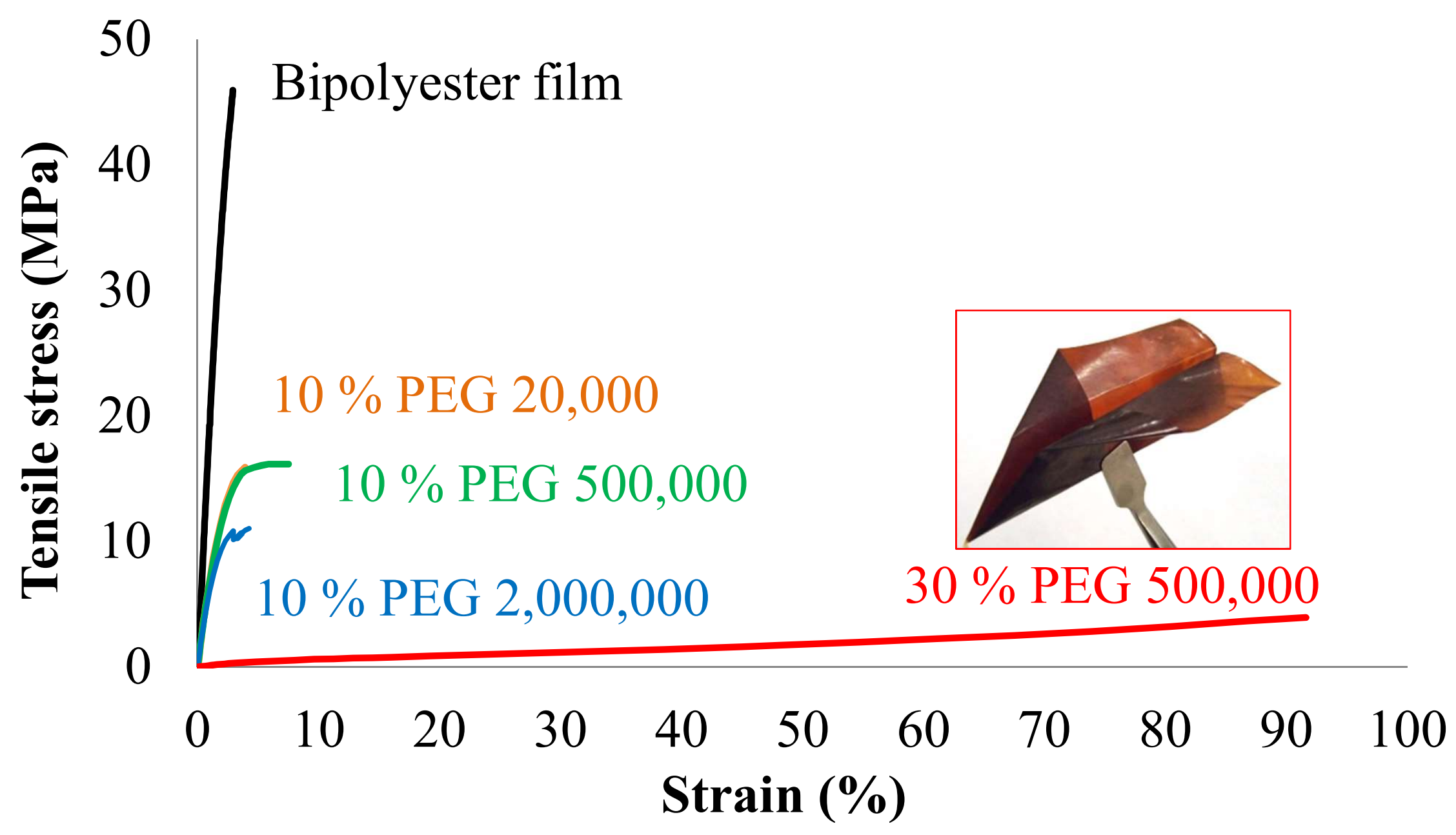

Fig. 6 


\section{DSC}

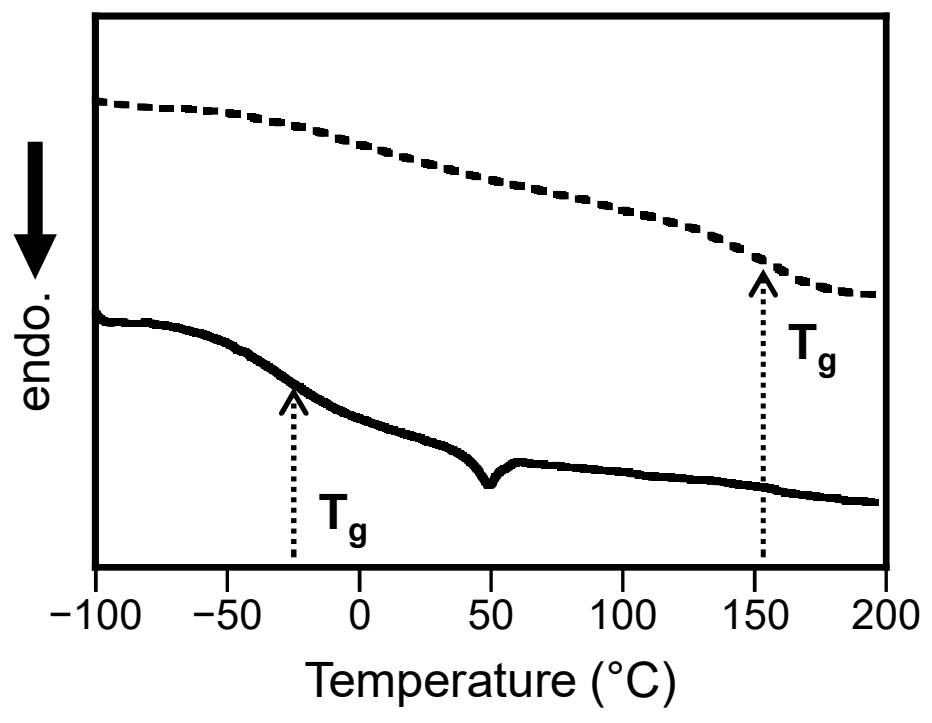

....... bipolyester film terpolyester film

\section{DMA}
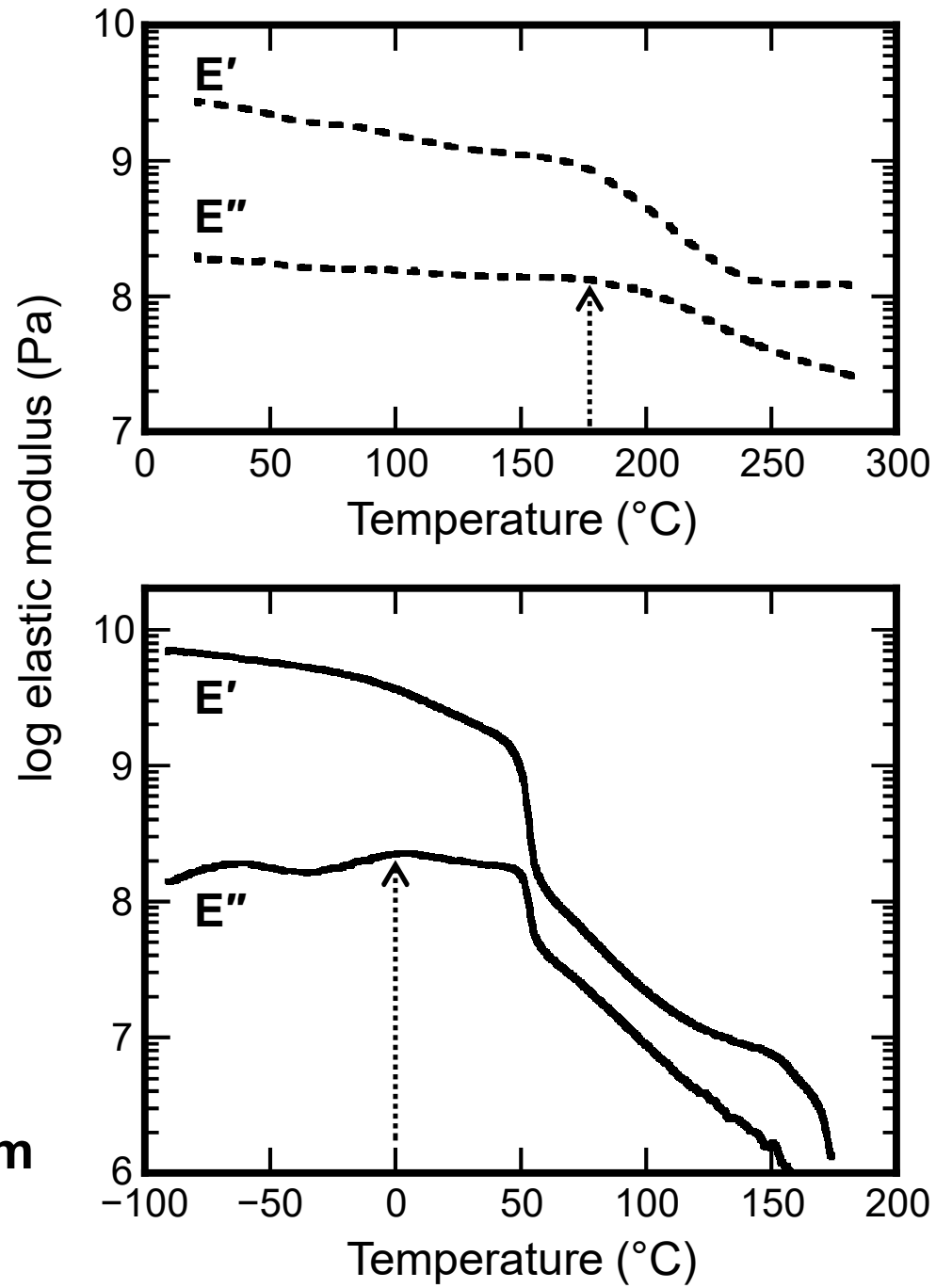

Fig. 7 


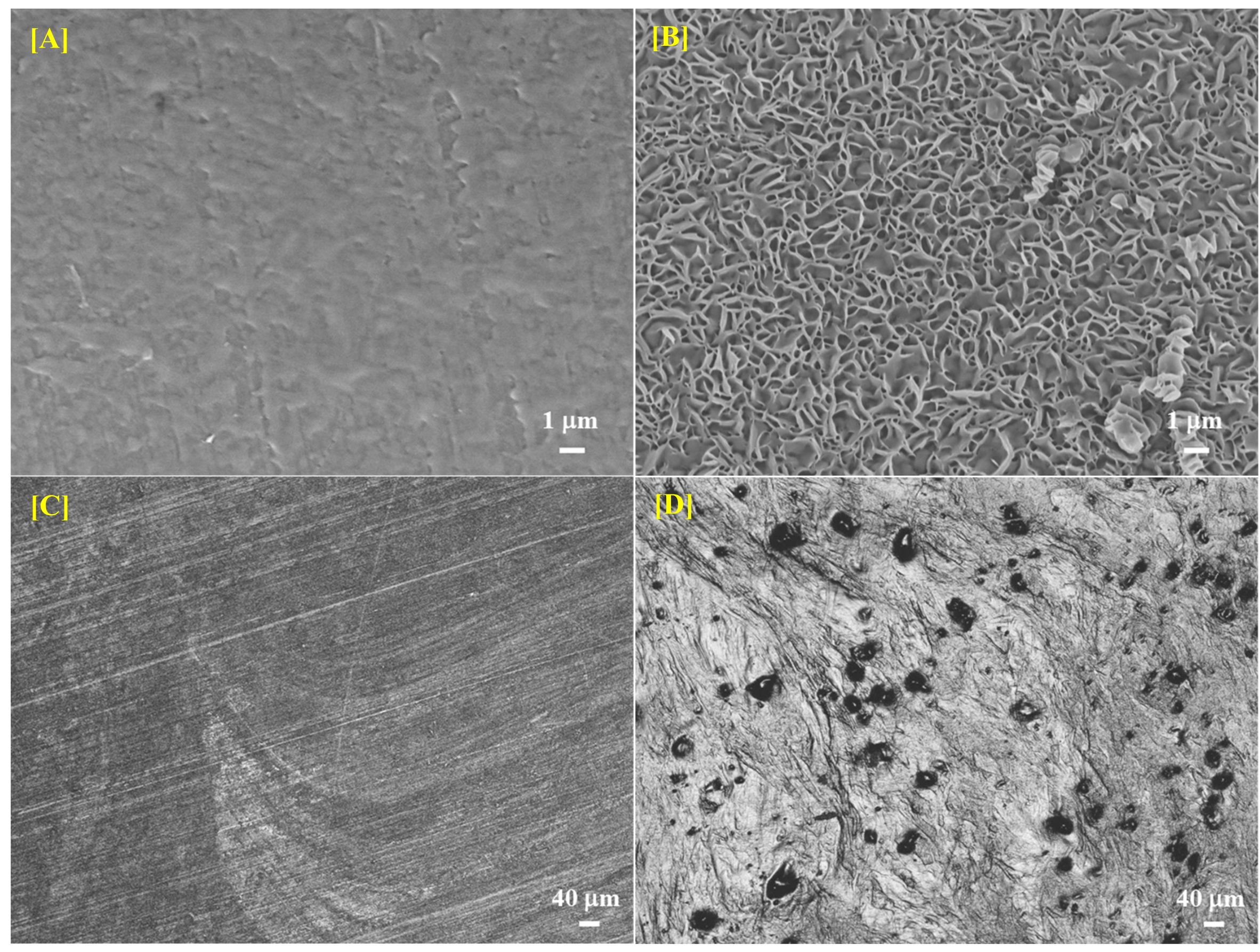

Fig. 8 


\section{Figure Captions}

Figure 1. FT-IR spectra for PEGL and its reduced derivatives with $\mathrm{NaBH}_{4}$ with varying reaction time.

Figure 2. FT-IR spectra for PEGL and PEGL-based bipolyester prepared at varying charged molar ratio of MA to PEGL, expressed as $\mathrm{COOH}_{(\mathrm{MA})} / \mathrm{OH}_{(\mathrm{PEGL})}$.

Figure 3. Esterification and possible side reactions between PEGL and MA. Formation of half-ester (or monoester) and diester are shown as in [1] and [2], respectively. Side reactions via carbon-carbon double bond of MA [3] and [4] (reported by Pandit and Nadkarni ${ }^{[26]}$ ) can be other types of crosslinking among PEGL molecules.

Figure 4. Electrochemical performance of EDLC with bipolyester film and terpolyester film as separator material. CV curves (left); Nyquist plot of EIS results (right).

Figure 5. Photographic images of separator films used in this study. Cellulosic paper is also shown as a reference.

Figure 6. Stress-strain curve for bipolyester and terpolyester films.

Figure 7. Thermal analyses of biopolyester and terpolyester films. DSC curves (left); DMA curves (right). Note: Above $\sim 170{ }^{\circ} \mathrm{C}$, the terpolyester film became so softened that $\mathrm{E}^{\prime}$ and $\mathrm{E}^{\prime \prime}$ values went out of the measurement limits $\left(\sim 10^{6} \mathrm{~Pa}\right)$.

Figure 8. Microscopic images of terpolyester films. Non-porous films before (A) and after (B) acetone wash observed under a scanning electron microscope. Non-porous film without $\mathrm{NaCl}$ treatment (C) and porous film with $\mathrm{NaCl}$ treatment (D) after acetone wash observed under a 3-D microscope. 
Table 1 Moldability and mechanical strength of lignin-based bipolyester film prepared with MA at varying charged molar ratio $\left(\mathrm{COOH}_{(\mathrm{MA})} / \mathrm{OH}_{(\mathrm{PEGL})}\right)$.

\begin{tabular}{ccccc}
\hline $\begin{array}{c}\mathrm{COOH}_{(\mathrm{MA})} / \mathrm{OH} \\
(\mathrm{mol} / \mathrm{mol})\end{array}$ & Moldability & $\begin{array}{c}\text { Tensile strength } \\
(\mathrm{MPa})\end{array}$ & $\begin{array}{c}\text { Tensile modulus } \\
(\mathrm{GPa})\end{array}$ & $\begin{array}{c}\text { Elongation } \\
(\%)\end{array}$ \\
\hline $1 / 9$ & $\sqrt{\mathrm{a})}$ & $5.4 \pm 2.1$ & $1.0 \pm 0.2$ & $0.7 \pm 0.2$ \\
$3 / 7$ & $\sqrt{ }$ & $27.1 \pm 7.1$ & $1.7 \pm 0.4$ & $2.6 \pm 0.6$ \\
$5 / 5$ & $\sqrt{ }$ & $21.1 \pm 5.3$ & $1.1 \pm 0.2$ & $3.5 \pm 1.7$ \\
$6.6 / 3.4$ & $\sqrt{ }$ & $45.6 \pm 10.6$ & $2.4 \pm 0.4$ & $2.6 \pm 0.4$ \\
$8 / 2$ & $\times \mathrm{b}$ & $\mathrm{ND}$ c) & $\mathrm{ND}$ & $\mathrm{ND}$ \\
$9 / 1$ & $\times$ & $\mathrm{ND}$ & $\mathrm{ND}$ & $\mathrm{ND}$ \\
\hline
\end{tabular}

a) good moldability: successful fabrication of flat film.

b) poor moldability: unsuccessful fabrication of flat film.

c) ND: not determined. 
Table 2 Electrochemical properties of EDLC assembled with porous and non-porous bipolyester and terpolyester film.

\begin{tabular}{lccc}
\hline \multicolumn{1}{c}{ Separator material } & $\begin{array}{c}\text { Specific } \\
\text { capacitance } \\
(\mathrm{F} / \mathrm{g})\end{array}$ & $\begin{array}{c}\text { Charge transfer } \\
\text { resistance } \\
(\Omega)\end{array}$ & $\begin{array}{c}\text { Intrinsic } \\
\text { resistance } \\
(\Omega)\end{array}$ \\
\hline PEGL/MA $^{\text {a) }}$ (non-pourous) & 4.3 & 486.6 & 117.9 \\
PEGL/MA (porous) & 59.1 & 28.7 & 26.5 \\
PEGL/MA/PEG) (non-porous) & 69.8 & 2.0 & 4.9 \\
PEGL/MA/PEG (porous) & 84.2 & 1.6 & 8.8 \\
Cellulosic separatorc) & 74.8 & 2.4 & 1.2 \\
\hline
\end{tabular}

a) bipolyester film prepared from PEGL and MA.

b) terpolyester film prepared from PEGL, MA, and PEG 500,000.

c) commercially available cellulose-based separator as a reference. 
Table 3 Mechanical properties of terpolyester film prepared from PEGL with MA and PEG analogues at the fixed molar ratio of 6.6/3.4.

\begin{tabular}{|c|c|c|c|}
\hline types of film & $\begin{array}{l}\text { Tensile strength } \\
\text { (MPa) }\end{array}$ & $\begin{array}{l}\text { Tensile modulus } \\
\text { (GPa) }\end{array}$ & $\begin{array}{c}\text { Elongation } \\
(\%)\end{array}$ \\
\hline PEGL/MA ${ }^{\mathrm{a})}$ & $45.6 \pm 10.6$ & $2.4 \pm 0.4$ & $2.6 \pm 0.4$ \\
\hline $\begin{array}{l}\text { PEGL/MA/PEG }{ }^{\mathrm{b})} \\
(10 \% \text { PEG 20,000) }\end{array}$ & $15.3 \pm 0.7$ & $0.7 \pm 0.2$ & $4.1 \pm 1.2$ \\
\hline $\begin{array}{l}\text { PEGL/MA/PEG } \\
(10 \% \text { PEG 500,000) }\end{array}$ & $14.7 \pm 4.2$ & $0.8 \pm 0.2$ & $5.3 \pm 2.5$ \\
\hline $\begin{array}{l}\mathrm{PEGL} / \mathrm{MA} / \mathrm{PEG} \\
(10 \% \mathrm{PEG} 2,000,000)\end{array}$ & $12.2 \pm 2.4$ & $0.7 \pm 0.2$ & $4.1 \pm 0.7$ \\
\hline $\begin{array}{l}\text { PEGL/MA/PEG } \\
(30 \% \text { PEG 500,000) }\end{array}$ & $3.8 \pm 0.6$ & $1.3 \times 10^{-2}$ & $94.1 \pm 5.0$ \\
\hline
\end{tabular}

a) bipolyester film prepared from PEGL and MA.

b) terpolyester film prepared from PEGL, MA, and PEG analogues.

c) PEG 20,000 (10 wt\% of total weight of PEGL\&MA) was added as the third ingredient. 
Table 4 Surface roughness of terpolyester films before (non-porous) and after (porous) treatment with $\mathrm{NaCl}$.

\begin{tabular}{cccc}
\hline & \multicolumn{3}{c}{ Surface roughness $(\mu \mathrm{m})$} \\
\cline { 2 - 4 } & $\mathrm{R}_{\mathrm{a}}$ & $\mathrm{R}_{\mathrm{p}}+\mathrm{R}_{\mathrm{v}}$ & $\mathrm{R}_{\mathrm{z}}$ \\
\hline Non-porous film & 2.3 & 81.5 & 66.4 \\
Porous film & 5.4 & 617.4 & 615.6 \\
\hline
\end{tabular}

$\mathrm{R}_{\mathrm{a}}$ : Arithmetic average roughness

$\mathrm{R}_{\mathrm{p}}$ : Maximum peak height in the assessed profile

$\mathrm{R}_{\mathrm{v}}$ : Maximum depth in the assessed profile

$\mathrm{R}_{\mathrm{z}}$ : 10-point average roughness

Detailed explanation is available at the website of ISO 4287 (surface roughness)

http://www.iso.org/obp/ui/\#iso:std:iso:4287:ed-1:vl:fr 